\title{
【研究简报】
}

\section{脉冲激光沉积 $\mathrm{SrBi}_{2} \mathrm{Ta}_{2} \mathrm{O}_{9}$ 铁电薄膜的研究}

\author{
杨平雄 郑立荣 林成鲁 \\ (中国科学院上海冶金研究所, 信息功能材料国家重点实验室, 上海 200050)
}

\section{关业词 SBT 脉冲激光沉积 铁电薄膜}

铁电薄膜存储器 (FRAM) 由于具有动态随机存储器 (DRAM) 快速读写功能和可擦写唯读 存储器 (EPROM) 非挥发性, 又具有抗辐照、功耗低等特性, 已成为国际上固态器件研究的一个 热点 ${ }^{[1]}$. 铁电存储器常用的铁电材料是 $\mathrm{Pb}\left(\mathrm{ZrTi}_{\mathrm{r}} \mathrm{O}_{3}(\mathrm{PZT})\right.$ 等氧化物钙钛矿结构材料. 由于 这些铁电材料抗疲劳性能较差, 阻碍了铁电存储器的商品化进程. de Araujo 等人 ${ }^{[2]}$ 报道了铋 系层状类钻钛矿结构的铁电蒋膜具有抗疲劳特性, 用这类铁电材料制作的铁电存储器, 在 $10^{12}$ 次重复开关极化后, 仍没有显示疲劳现象, 并且具有很好的信息储存寿命和较低的漏电流.

$\mathrm{SrBi}_{2} \mathrm{Ta}_{2} \mathrm{O}_{9}$ (SBT) 属于铋系层状类钙钛矿铁电体, 它的晶格结构是由两个具有铁电性的类 钙钛矿单元 $\mathrm{SrTaO}_{3}$ 在非铁电性的 $\mathrm{Bi}_{2} \mathrm{O}_{2}$ 层之间沿着准四方的 $c$-轴堆积而成. 由于铋氧层的 “缓冲吸收”作用, 使得 SBT 薄膜具有抗疲劳特性. 脉冲激光沉积 (PLD) 法在高温氧化物超导 薄膜的研制上获得巨大成功之后 ${ }^{[3]}$, 已在铁电体、生物陶瓷、铁氧体、半导体、耐磨材料等薄膜 的制备中得到广泛应用. PLD 具有制备复杂组分的薄膜材料、薄膜组分容易控制、生长速率 快、沉积参数易调等特点.

本文采用 PLD 方法在 $\mathrm{Pt} / \mathrm{Ti} / \mathrm{SiO}_{2} / \mathrm{Si}$ 衬底上成功地制备了 $\mathrm{SBT}$ 薄膜. 并用 $\mathrm{X}$ 射线衍射 (XRD)、扩展电阻测量技术 (ASR) 及 Sawyer-Tower 电路等分别研究了 SBT 薄膜的结构、厚度 及铁电特性.

\section{1 实验}

实验装置同文献[4], ArF 脉冲准分子激光器 (Lambda Physik LPX120icc, 波长 $193 \mathrm{~nm}$ ) 的 能量为 $160 \mathrm{~mJ}$, 脉冲频率为 $3 \mathrm{~Hz}$. SBT 固体靶由 $\mathrm{SrCO}_{3}, \mathrm{Bi}_{2} \mathrm{O}_{3}$ 和 $\mathrm{Ta}_{2} \mathrm{O}_{5}$ 经混合球磨、预烧和 压模, 最终烧结获得. 衬底为 $\mathrm{Pt}(60 \mathrm{~nm}) / \mathrm{Ti}(15 \mathrm{~nm}) / \mathrm{SiO}_{2} / \mathrm{Si}$, 其中 $\mathrm{Pt} / \mathrm{Ti}$ 利用超高真空电子 束蒸发仪 (Balzers UMS500P) 制备. PLD 过程中, 通入纯氧保护气体, 工作气压为 $30 \mathrm{~Pa}$, 保持 袝底温度为 $400^{\circ} \mathrm{C}$ 或 $500^{\circ} \mathrm{C}$, 将沉积的 SBT 薄膜在 $200 \sim 800^{\circ} \mathrm{C}$ 氧气气氛保护下退火 $1 \sim 2 \mathrm{~h}$, 再 由超高真空电子束蒸发仪沉积 $30 \mathrm{~nm}$ 厚度的 $\mathrm{Pt}$ 作上电极.

\section{2 结果与讨论}

图 1(a) 为 SBT 薄膜 XRD 谱. SBT 薄膜的择优取向为 (115), 与靶的择优取向一致(图 1 (b)). 由 Scherer 半峰宽公式得到 SBT 薄膜的平均晶粒约为 $200 \mathrm{~nm}$, 铂电极取向为 (111). 扩 展电阻技术测得 SBT 薄膜的厚度约为 $350 \mathrm{~nm}$.

图 2 为 $\mathrm{Pt} / \mathrm{SBT} / \mathrm{Pt}$ 薄膜电容电滞回线. 从图上可见, 在 $\pm 5 \mathrm{~V}$ 电压时电滞回线已趋于饱 


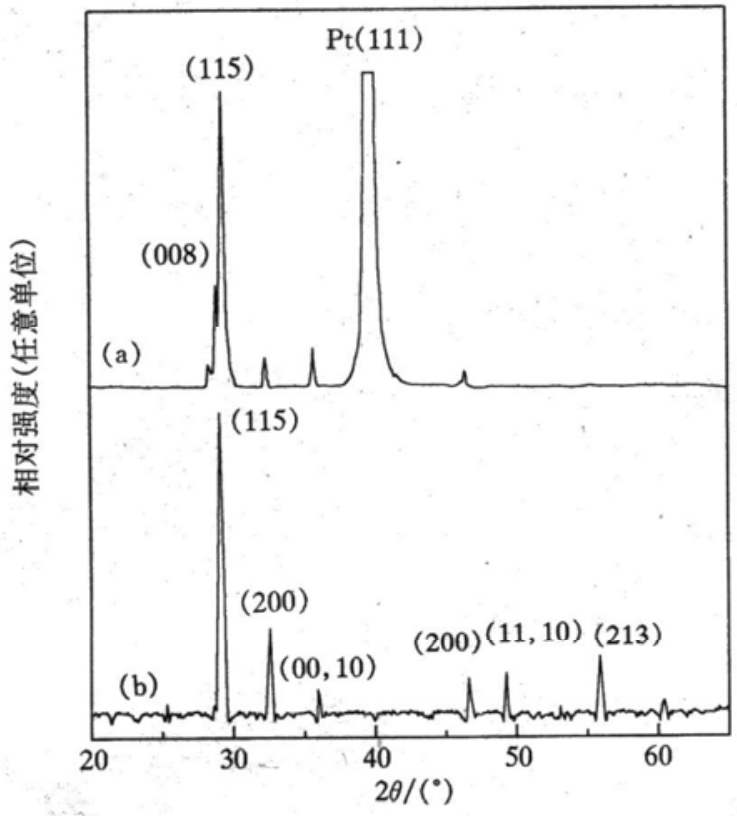

图 1 SBT 薄膜 $(a)$ 和靶 $(b)$ 的 XRD 谱

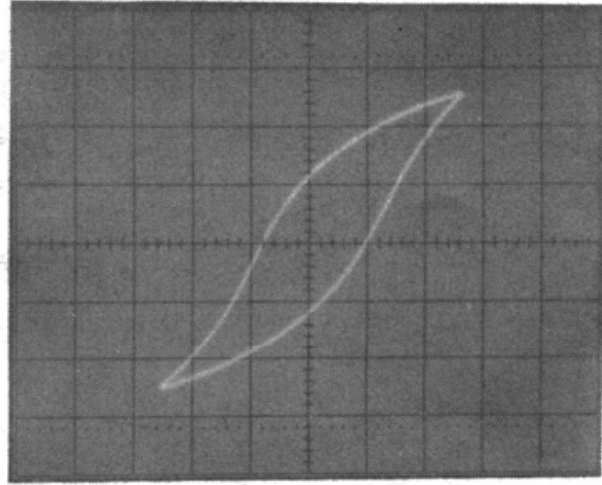

图 $2 \mathrm{Pt} / \mathrm{SBT} / \mathrm{Pt}$ 薄膜电容电滞回线 $X$ 轴为电压 $(2 \mathrm{~V} / \mathrm{div}), Y$ 轴为极化 $\left(7 \mu \mathrm{C} \cdot \mathrm{cm}^{-2} / \mathrm{div}\right)$

和, 其剩余极化强度 $P_{\mathrm{r}}$ 为 $8.4 \mu \mathrm{C} / \mathrm{cm}^{2}$, 矫顽电场 $E_{\mathrm{c}}$ 为 $57 \mathrm{kV} / \mathrm{cm}$, 与文献[2]相近. 图 3 表示 薄膜的剩余极化 $P_{\mathrm{r}}$ 值和最大极化 $P_{\max }$ 值与电压之间的关系. 由图可见, 在 $5 \mathrm{~V}$ 电压时, $P_{\mathrm{r}}$ 值 已趋于饱和, 说明该薄膜用于 FRAM 可与集成电路 (IC) 工作电压兼容, 在 $5 \mathrm{~V}$ 下可达到 开关.

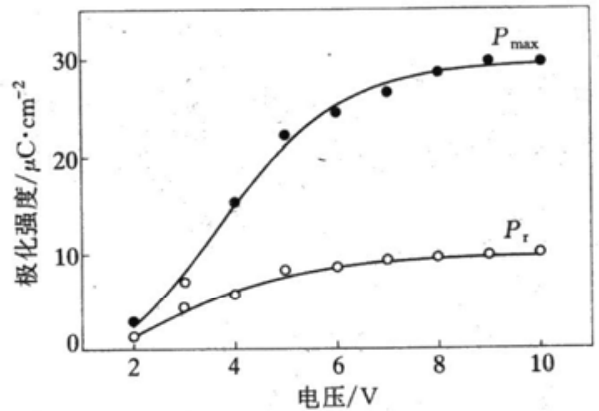

图 3 SBT 薄膜剩余极化 $P_{\mathrm{r}}$ 值和最大极化 $P_{\max }$ 与电压之间的关系

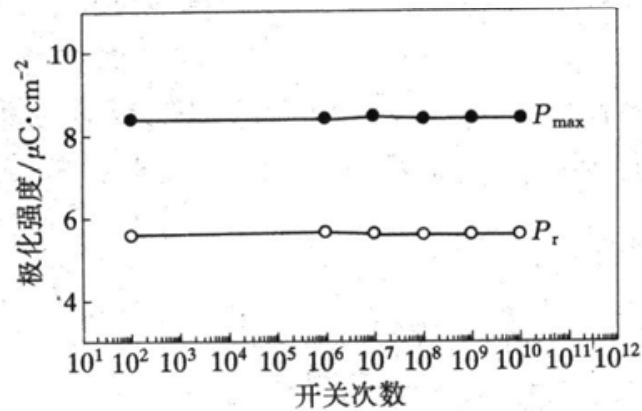

图 4 外加电压 $4 \mathrm{~V}, 1 \mathrm{MHz}$ 方波情况下, SBT 薄

膜电容的疲劳测试曲线

图 4 表示在外加电压 $\pm 4 \mathrm{~V}, 1 \mathrm{MHz}$ 方波情况下, SBT 薄膜电容的疲劳测试曲线. 表明在 $10^{10}$ 次开关极化后, SBT 薄膜电容没有显示疲劳现象, 说明 SBT 材料的确具有优良的抗疲劳 特性.

\section{3 结论}

用 $\mathrm{PLD}$ 方法在 $\mathrm{Pt} / \mathrm{Ti} / \mathrm{SiO}_{2} / \mathrm{Si}$ 衬底上成功地制备了 $\mathrm{SBT}$ 薄膜, 薄膜的晶面取向以 (115) 